\title{
Uso de Tecnologia da Informação e Comunicação YouTube para produção e divulgação de conteúdo sobre o curso de medicina: experiências dos acadêmicos
}

\author{
Use of the Information and Communication Technology YouTube for \\ production and diffusion of content about a medical course: students' \\ experiences
}

\section{Uso de la tecnología de la información y la comunicación de YouTube para la producción y difusión de contenido sobre el curso de medicina: experiencias de los estudiantes}

Marcela Costa de Almeida Silva ${ }^{1, a}$

marcelascosta24@gmail.com | http://orcid.org/o000-0001-5211-055X

Paulo Ricardo dos Santos ${ }^{1, b}$

paulo.ricardobiomed@gmail.com | http://orcid.org/oooo-0001-7168-4196

Letícia Cristina Oliveira Dias ${ }^{1, d}$

leticiacod@gmail.com | https://orcid.org/o0oo-0001-6504-6200

Johnatan Reis da Silva ${ }^{2, c}$

johnatanreis@gmail.com | https://orcid.org/oooo-0003-2856-2489

Aridiane Alves Ribeiro ${ }^{1, e}$

aridiane@ufg.br | https://orcid.org/oooo-0003-2702-9332

${ }^{1}$ Universidade Federal de Jataí, Unidade Acadêmica Especial de Ciências da Saúde, Curso de Medicina. Jataí, GO, Brasil.

${ }^{2}$ Universidade Federal de Uberlândia, Faculdade de Medicina. Uberlândia, MG, Brasil.

a Graduanda em Medicina pela Universidade Federal de Jataí.

b Graduando de Medicina pela Universidade Federal de Jataí.

c Graduação em Jornalismo pela Universidade de Brasília.

d Graduação em Saúde Coletiva pela Universidade de Brasília.

e Doutorado em Enfermagem pela Universidade de São Paulo.

\section{RESUMO}

Este artigo objetivou descrever a experiência e a avaliação do uso de tecnologias digitais como estratégia de divulgação por discentes de um curso de medicina criado pelo Programa Mais Médicos. Trata-se de relato de experiência sobre o desenvolvimento de um canal no YouTube para divulgar a graduação de medicina da Universidade Federal de Jataí. Procedeu-se avaliação quantitativa e qualitativa dos indicadores do canal. A partir de setembro de 2017, a equipe se organizou em cinco grupos de trabalho: pauta, redação, atualização, gravação e edição. Ressaltam-se como resultados: 17 vídeos, 607 inscritos e 34.757 visualizações. Percebeuse engajamento e demanda de informações pelos usuários, aumento contínuo do número de acessos e picos em períodos de abertura de vagas de vestibulares e comentários. As experiências contribuíram para aprimoramento de habilidades extracurriculares dos estudantes envolvidos. O canal pôde auxiliar ingressantes no Ensino Superior na tomada de decisão e motivação pela escolha do curso.

Palavras-chaves: Multimídia de comunicação; Educação superior; Educação médica; Tecnologia da informação; Medicina. 


\title{
ABSTRACT
}

This article aimed at describing the experience and evaluation of use of digital technologies by medical students as a dissemination strategy of a course created by "More Doctors" Program. This is an experience report on the development of a YouTube channel to publicize the medical degree at the Federal University of Jataí. Quantitative and qualitative evaluation of channel indicators was carried out. From September 2017, the team was organized into five working groups: timetable, writing, updating, recording and editing. The main results were 17 videos, 603 subscribers and 34,757 views. We noticed users' engagement and direct demand for information, a continuous increase in the number of accesses, and peaks in vestibular opening periods, in addition to comments. The experiences contributed to improvement of students' extracurricular skills. The channel was able to assist interested people in Higher Education in decision making and motivation for choosing the course.

Keywords: Multimedia; Higher education; Medical education; Information technology; Medicine.

\section{RESUMEN}

Este artículo describe la experiencia y evaluación del uso de las tecnologías digitales como estrategia de difusión por parte de los estudiantes de un curso de medicina creado por el Programa "Mais Médicos". Relato de experiencia sobre el desarrollo de un canal de YouTube para dar a conocer la graduación médica de la Universidad Federal de Jataí. Se realizó una evaluación cuantitativa y cualitativa de los indicadores del canal. En septiembre de 2017, equipo se organizó en grupos: agenda, redacción, actualización, grabación y edición. Resultados: 17 videos, 603 suscriptores y 34,757 visualizaciones. Se notó el compromiso y demanda de información de los usuarios, aumento continuo en el número de accesos y picos en los períodos de apertura de exámenes de ingreso. Las experiencias contribuyeron a la mejora de las habilidades extracurriculares de los estudiantes. El canal pudo ayudar a los estudiantes en la toma de decisiones para elegir el curso.

Palabras clave: Multimedia; Educación superior; Educación médica; Tecnología de la información; Medicina.

\begin{abstract}
Contribuição dos autores:
Concepção e desenho do estudo: Marcela Costa de Almeida Silva, Paulo Ricardo dos Santos, Letícia Cristina Oliveira Dias, Johnatan Reis da Silva, Aridiane Alves Ribeiro.

Aquisição, análise ou interpretação dos dados: Marcela Costa de Almeida Silva, Paulo Ricardo dos Santos, Letícia Cristina Oliveira Dias, Johnatan Reis da Silva, Aridiane Alves Ribeiro.

Redação do manuscrito: Marcela Costa de Almeida Silva, Paulo Ricardo dos Santos, Letícia Cristina Oliveira Dias, Johnatan Reis da Silva, Aridiane Alves Ribeiro.

Revisão crítica do conteúdo intelectual: Aridiane Alves Ribeiro.
\end{abstract}

Declaração de conflito de interesses: não há.

Fontes de financiamento: não houve.

Considerações éticas: não há.

Agradecimentos/Contribuições adicionais: não há.

Histórico do artigo: submetido: 15 set. 2020 | aceito: 22 dez. 2020 | publicado: 30 jun. 2021.

Apresentação anterior: não há.

Licença CC BY-NC atribuição não comercial. Com essa licença é permitido acessar, baixar (download), copiar, imprimir, compartilhar, reutilizar e distribuir os artigos, desde que para uso não comercial e com a citação da fonte, conferindo os devidos créditos de autoria e menção à Reciis. Nesses casos, nenhuma permissão é necessária por parte dos autores ou dos editores. 


\section{INTRODUÇÃO}

Este trabalho busca compartilhar experiências relacionadas à elaboração de um canal no YouTube como ferramenta digital de comunicação e divulgação junto à sociedade sobre o curso de medicina de uma universidade federal do interior do estado de Goiás.

No atual contexto de mudanças exponenciais em relação ao compartilhamento de informações, ao estilo de vida e ao trabalho, a curiosidade sobre a vida universitária é uma realidade latente, vide o anseio e preocupação de jovens e suas famílias quanto ao ingresso no Ensino Superior mediante a pandemia do novo coronavírus (FONTOURA, 2020).

O interesse pelo Ensino Superior atravessa a própria organização social no país, uma vez que o assunto é abordado em diferentes aspectos da rotina brasileira, como no estilo musical 'sertanejo universitário'; em novelas e séries, cujo enredo aborda a vida de estudantes universitários; e ainda nos noticiários que recorrentemente contam as trajetórias de esforço de jovens no vestibular (NUNES; FAVACHO, 2019), especialmente dos cursos de alta concorrência, como o de medicina.

O meio digital é uma das maneiras mais utilizadas atualmente para se obter informações sobre o Ensino Superior, especialmente a respeito dos cursos de medicina (FONTOURA, 2020). Nesse sentido, conteúdos digitais são importantes ferramentas de divulgação. O meio digital é atualmente um norteador fundamental na produção de linguagens, cuja influência impacta, como em uma retroalimentação, seu caráter e relação com a sociedade. Sua informalidade, indefinição e indistinção peculiares possibilitam amplo e diversificado alcance social (SILVA; GRILLO, 2019). A Internet é um importante meio de comunicação (PELLEGRINI; REIS; MONÇÃO; OLIVEIRA, 2010). Lidar com tecnologias digitais como meio de divulgação e informação traduz uma tendência mundial que deve ser abarcada e aprendida ainda no contexto educacional e universitário (PELLEGRINI; REIS; MONÇÃO; OLIVEIRA, 2010).

No mundo pós-moderno, as pessoas adquiriram uma outra característica, pois são 'seres multimídia', dadas as estatísticas de pessoas conectadas e que compartilham algum tipo de mídia (PELLEGRINI; REIS; MONÇÃO; OLIVEIRA, 2010). Estes dados estão em franco crescimento durante a pandemia. Uma pesquisa das Nações Unidas divulgou que quase quatro bilhões de pessoas estão na internet no mundo. Número que representa mais de 50\% da população do planeta (MEASURING..., 2019). Essas pessoas estão se comunicando por diferentes modos, tais quais, palavras, imagens e vídeos (PELLEGRINI; REIS; MONÇÃO; OLIVEIRA, 2010). Nesse contexto, insere-se o YouTube, um serviço on-line de vídeos criado nos anos 2000 que possui um bilhão de usuários, mundialmente, são seis bilhões de horas de vídeo assistidas por mês (ARSLAN; GÖNÜLTAS; GÖKMEN; ÖZMAN, 2019).

Apesar do aumento do compartilhamento de informações no mundo, inclusive sobre o curso de medicina, não se observa a mesma democratização do acesso a outros tipos de serviços, como o Ensino Superior. É possível mencionar alguns avanços, como o acesso ampliado a universidades federais pelo Sistema de Seleção Unificada (SISU) em 2010, e, no caso da graduação em medicina, a criação do programa do governo federal Mais Médicos em 2013. Um dos pilares do programa é a expansão do número de vagas para os cursos de medicina e residência médica em várias regiões do país (CASTELO BRANCO; BONTEMPO; SARAIVA; AMARAL, 2016; GERMANO, 2017). Todavia, o público do curso se mantém muito semelhante ao perfil do acadêmico de medicina do século 20: homens, de classes elevadas, pois mulheres eram consideradas inaptas para o exercício da medicina. A maior mudança, neste caso, foi de gênero, com mais mulheres cursando a graduação (FIOROTTI; ROSSONI; MIRANDA, 2007).

Considerando este contexto, é fundamental o melhor uso das ferramentas digitais para compartilhar informações da vida acadêmica para a comunidade em geral. Tal conjuntura sinaliza a importância de se 
utilizar tecnologias de comunicação digital para a disseminação da realidade do estudante de medicina, um curso de graduação historicamente distanciado da população (REGO, 2018).

Guiado por tais pressupostos e mediante a carência de informações sobre o curso de graduação no qual ingressaram, um grupo de estudantes de medicina idealizou e teve a iniciativa de implementar um projeto piloto de divulgação da realidade acadêmica e social no qual estavam inseridos. Portanto, com este artigo, objetiva-se descrever a experiência e a avaliação do uso de tecnologias digitais como estratégia de divulgação por discentes de um curso de medicina criado pelo Programa Mais Médicos.

\section{ESTRATÉGIA METODOLÓGICA}

Trata-se de um relato de experiência sobre o desenvolvimento de um projeto piloto para criação de ambiente virtual para compartilhamento e divulgação das atividades acadêmicas sobre o curso de medicina da Universidade Federal de Jataí (UFJ), acessado por meio da plataforma YouTube.

A iniciativa do projeto piloto partiu dos discentes frente à falta de informação encontrada sobre a cidade, a universidade e o curso de medicina. No período de elaboração do projeto piloto, fez-se um levantamento inicial sobre a qualidade e tipo de informação encontrada relacionada a esses assuntos em sites de pesquisa na internet e percebeu-se que as informações ofertadas eram escassas e genéricas. Além disso, não respondiam a questionamentos levantados por pessoas interessadas em ingressar na UFJ, tais como, custo de vida da cidade, oferta de locais de moradia, projeto pedagógico do curso e métodos de ensino e aprendizagem adotados pela faculdade. $O$ site institucional da universidade carecia de informações, visto ser um curso novo e sem informativos oficiais atualizados. Assim, percebeu-se a necessidade de divulgação dessas informações tanto para comunidade interna quanto externa à universidade.

A concepção e desenvolvimento do ambiente virtual no YouTube foram realizados a partir da estratégia metodológica peer education ou educação entre pares (ADRIÃO, 2010). Ou seja, todas as etapas de criação do ambiente virtual e de suas atividades foram lideradas pelos próprios alunos. As discussões também conformaram espaços de construção de conhecimento, liderança, gestão e trabalho colaborativo/em equipe entre os acadêmicos (ADRIÃO, 2010).

O projeto piloto 'Canal da medicina: De olho na Med Jataí' foi implementado no período de setembro de 2017 a dezembro de 2018. A concepção do conteúdo, design e manutenção do ambiente virtual foi dos discentes. O YouTube, nessa circunstância, foi escolhido por se tratar de uma Tecnologia da Informação e Comunicação (TIC) gratuita. A TIC trata-se de recursos que potencializam o processo de informação e comunicação por deixá-lo ágil, acessível e transpor barreiras geográficas (SILVA; GRILO, 2019; LIBARDI; DUARTE; LIMA; MONTEIRO, 2018; TAPIA-JARA; SÁNCHEZ-ORTÍZ; VIDAL-SILVA, 2020).

A avaliação do uso da TIC YouTube como estratégia de divulgação do recém-criado curso de medicina pelo Programa Mais Médicos incluiu indicadores quantitativos e qualitativos. Procedemos abordagem quantitativa dos dados produzidos pelo YouTube, especificamente: faixa etária e sexo dos inscritos, números de acessos e de usuários do canal, bem como número de visualizações. Para análise foi feito cálculo de números absolutos, percentuais, médias e medianas para as variáveis acima mencionadas.

O indicador qualitativo foi constituído pelos depoimentos, a partir dos quais, realizou-se análise qualitativa, com uso do software de análise qualitativa NVivo (MINAYO, 2010). Para tanto, procedeu-se a ordenação dos dados. Isto é, os depoimentos foram extraídos dos comentários dos vídeos do Canal no YouTube e organizados no Google Docs/Google Drive. Posteriormente, o material foi transportado para o NVivo.

No software, o material foi identificado e, então, lido horizontal e verticalmente. A partir disso, realizou-se a codificação do conteúdo em unidades de sentido e tópicos de informação, seguindo o objetivo da avaliação. O material codificado foi organizado em temas considerando a relevância e frequência dos assuntos. Para apresentação dos temas utilizou-se quadro e nuvens de palavras elaborados no NVivo (MINAYO, 2010). 
Este estudo dispensa a avaliação do Comitê de Ética em Pesquisa, por se tratar de um relato de experiência. Apesar disso, seguimos todos os preceitos éticos na elaboração deste artigo. Realizamos anonimização das informações do canal para assegurar o sigilo, anonimato e privacidade dos usuários. Isto é, em nenhum momento citamos nomes ou dados dos internautas. Além disso, os autores de comentários tiveram seus nomes substituídos por outros fictícios, escolhidos segundo renomados profissionais da história da medicina.

\section{RESULTADOS}

Os resultados estão organizados conforme o seguinte: i) organização da dinâmica de trabalho e concepção do ambiente virtual 'De olho na Med', ii) avaliação da abrangência e conteúdo, iii) avaliação qualitativa depoimentos.

\section{Organização da dinâmica de trabalho e concepção do ambiente virtual 'De olho na Med'}

Esta fase consistiu no planejamento e concepção do canal. A primeira reunião de trabalho ocorreu em maio de 2017. Primordialmente, os discentes objetivaram postar vídeos explicativos no YouTube sobre temas relacionados ao curso de medicina da Universidade Federal de Goiás (UFG), Regional Jataí, atualmente emancipada para Universidade Federal de Jataí. Mediante discussão entre os envolvidos, a delimitação do projeto foi expandida para criação de perfis nas mídias sociais Facebook e Instagram, cujo intuito era dar suporte ao canal no YouTube e apresentar conteúdos próprios e mais dinâmicos.

Os alunos se organizaram em pequenos grupos de acordo com as habilidades individuais a fim de desenvolver as atividades pertinentes à produção de conteúdo e design do canal e mídias sociais. Quatro equipes foram formadas: de relações, da atualização, de gravações e de edição. Para facilitar e otimizar a gestão, cada equipe contava com um coordenador. Este, por sua vez, tinha a função de discutir as atribuições dos membros da equipe e auxiliar nas necessidades e dificuldades deles.

O grupo de relações contou com quatro estudantes. Entre as atividades desenvolvidas por esses alunos, vale ressaltar a escolha das pessoas a serem entrevistadas, o contato com as ligas e centro acadêmico (CA) e atlética, a comunicação entre o projeto e as pessoas que seriam entrevistadas, o agendamento do horário e local para gravações, bem como a promoção do projeto nas mídias sociais.

A atualização foi formada por três acadêmicos, que ficaram responsáveis pelas atividades de pesquisa sobre o assunto do vídeo a ser gravado, pelo questionário (script) para entrevista, pela pesquisa de assuntos de interesse da comunidade e por redigir a entrevista em texto para ser utilizada em blog, trabalhos e resumos.

Já a equipe de gravações, composta por quatro alunos, ficou responsável por desenvolver as atividades de preparar local e material para gravações, gravar os vídeos, confirmar se o conteúdo estava de acordo com a pauta e enviá-los para a edição.

Dando continuidade ao fluxograma de atividades, a equipe da edição contou com dois colaboradores, os quais desempenhavam as atividades de edição de vídeos mantendo um padrão, confirmavam se os vídeos estavam de acordo com a pauta preestabelecida, verificavam a qualidade do processo, além de pesquisar novos formatos para os vídeos do projeto, como também sugestões de alterações do próprio projeto.

A dinâmica de trabalho dos pequenos grupos era pautada pela produção de cada vídeo. As decisões das pautas eram feitas em conjunto com todos do projeto. Uma vez decidida a pauta e a meta de execução, davase início ao fluxograma do projeto, culminando na avaliação do vídeo desenvolvido pela equipe e posterior postagem na plataforma YouTube. Essa mesma dinâmica usada para criação e postagem de material para 
o YouTube foi utilizada para postagem de material no Facebook e no Instagram. A Figura 1 demonstra o fluxograma elaborado pelos discentes para organização da produção dos vídeos para o canal.

Fluxograma do projeto piloto

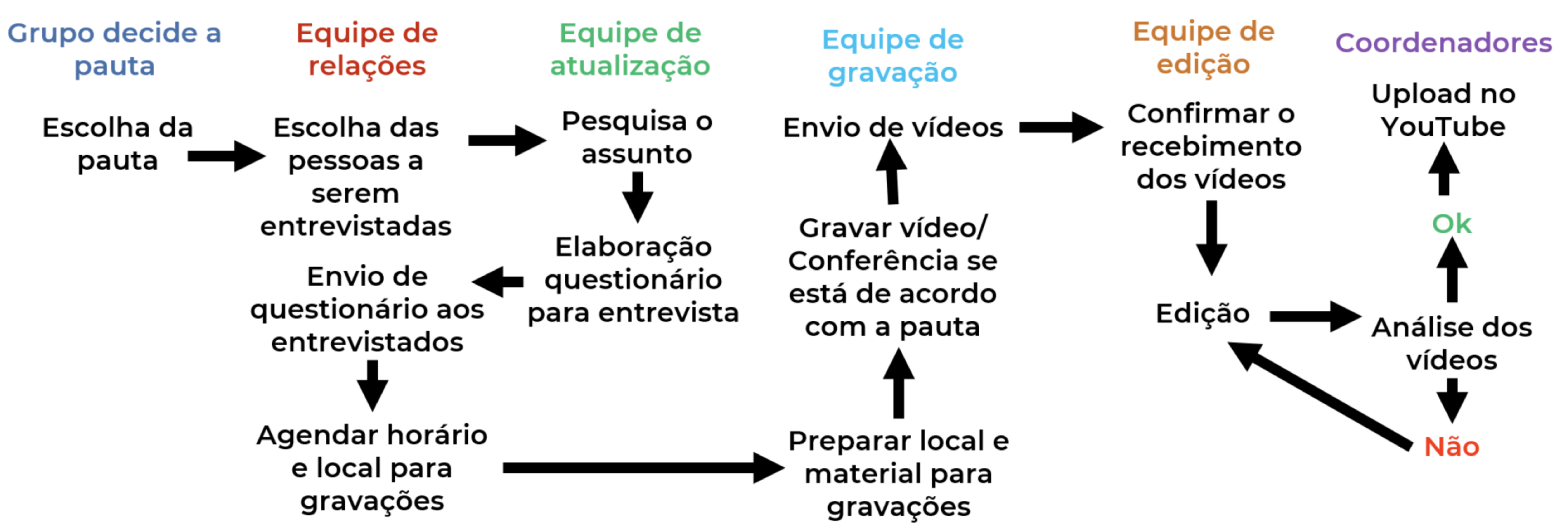

Figura 1 - Fluxograma de atividades desempenhadas por cada grupo do projeto Fonte: elaboração dos autores.

Para edição dos vídeos, utilizamos editor de vídeos on-line gratuito do próprio YouTube, no qual é possível reunir vários vídeos, fazer cortes, adicionar legendas e já publicar o conteúdo no YouTube. Por ser um projeto dinâmico, as atividades de cada membro e a composição das equipes foram alteradas diversas vezes no período de vigência desse primeiro ano, mantendo-se o cerne das atividades como já descritas anteriormente para cada equipe.

\section{Avaliação da abrangência}

O número de inscritos no canal 'De olho na Med' foi de 607 no período de setembro de 2017 a junho de 2020. Dos quais, 314 (51,7\%) se identificaram como sexo feminino, e 293 (48,3\%) sexo masculino. A Figura 2 demonstra a variação de idade desta população, sendo a faixa etária de 18 a 25 a mais alta, correspondendo a $78 \%$.

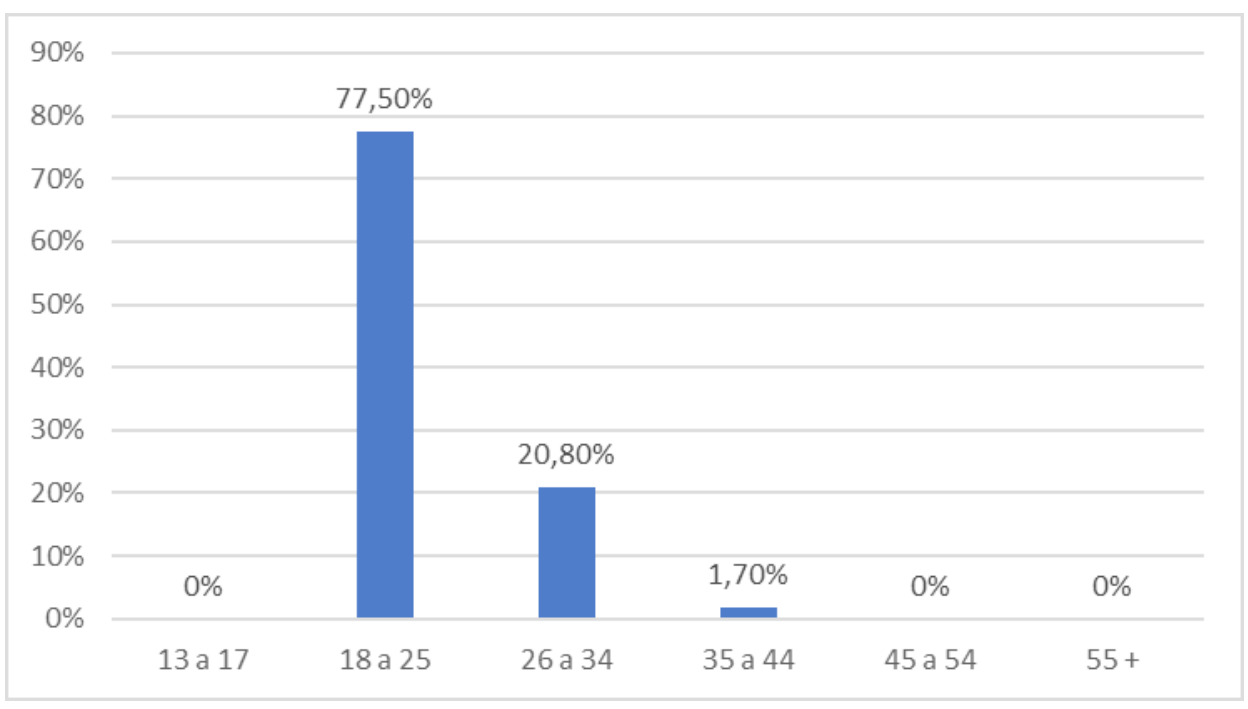

Figura 2 - Idade dos inscritos no canal 'De olho na Med', no período de setembro de 2017 a junho de 2020. Fonte: elaboração dos autores. 
No tocante ao alcance do canal no YouTube, observou-se que o número de inscritos aumentou a cada semestre, especialmente nos dois primeiros anos, período correspondente ao projeto-piloto. Isto é, quando o canal estava correspondendo com os internautas e postando novos vídeos. Apesar disso, o canal continuou recebendo novos usuários nos semestres posteriores ao término do piloto, que correspondem aos anos de 2019 e 2020, como demonstrado na Figura 3.

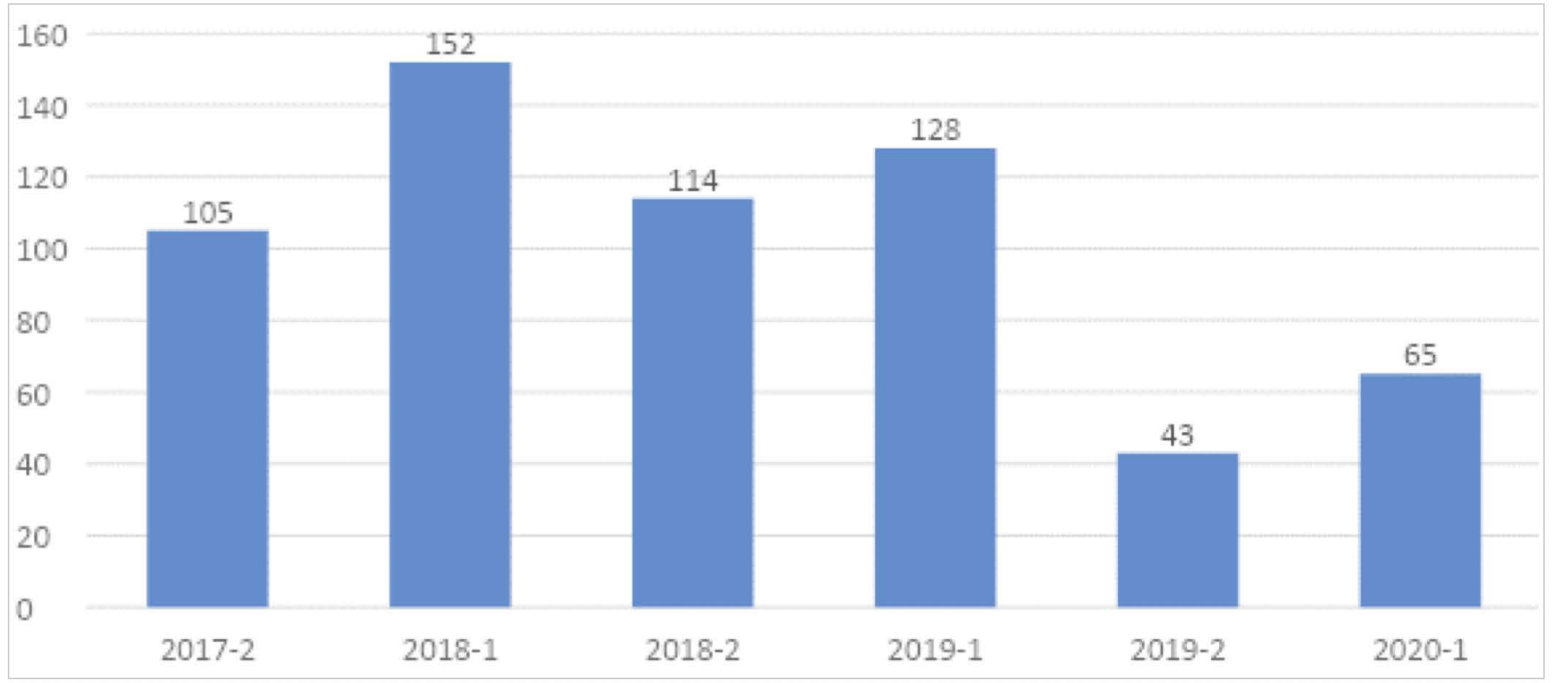

Figura 3 - Novos inscritos por semestre no canal ‘De olho na Med', no período de setembro de 2017 a junho de 2020 Fonte: elaboração dos autores.

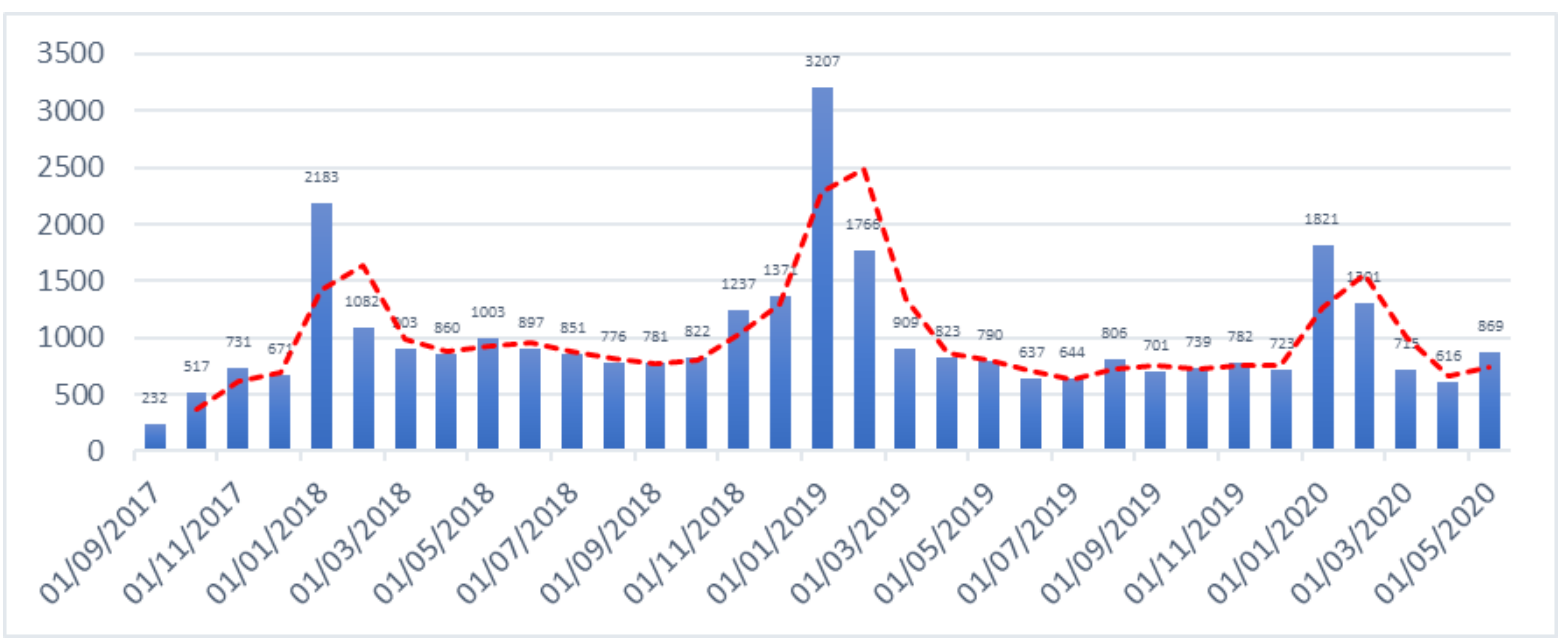

Figura 4 - Número de visualizações no canal ‘De Olho na Med' no período de setembro de 2017 a junho de 2020 Fonte: elaboração dos autores.

A Figura 4 evidencia o número bimestral de acessos ao canal 'De olho na Med'. Destaca-se também a ciclicidade de acessos ao canal, com picos de crescimento de acesso anuais, sempre em janeiro. Essa ciclicidade pode ser atribuída ao período do ano de abertura do SISU e posterior ao Exame Nacional do Ensino Médio (ENEM). O que também é visto nas ascendências pontuais da Figura 5. 


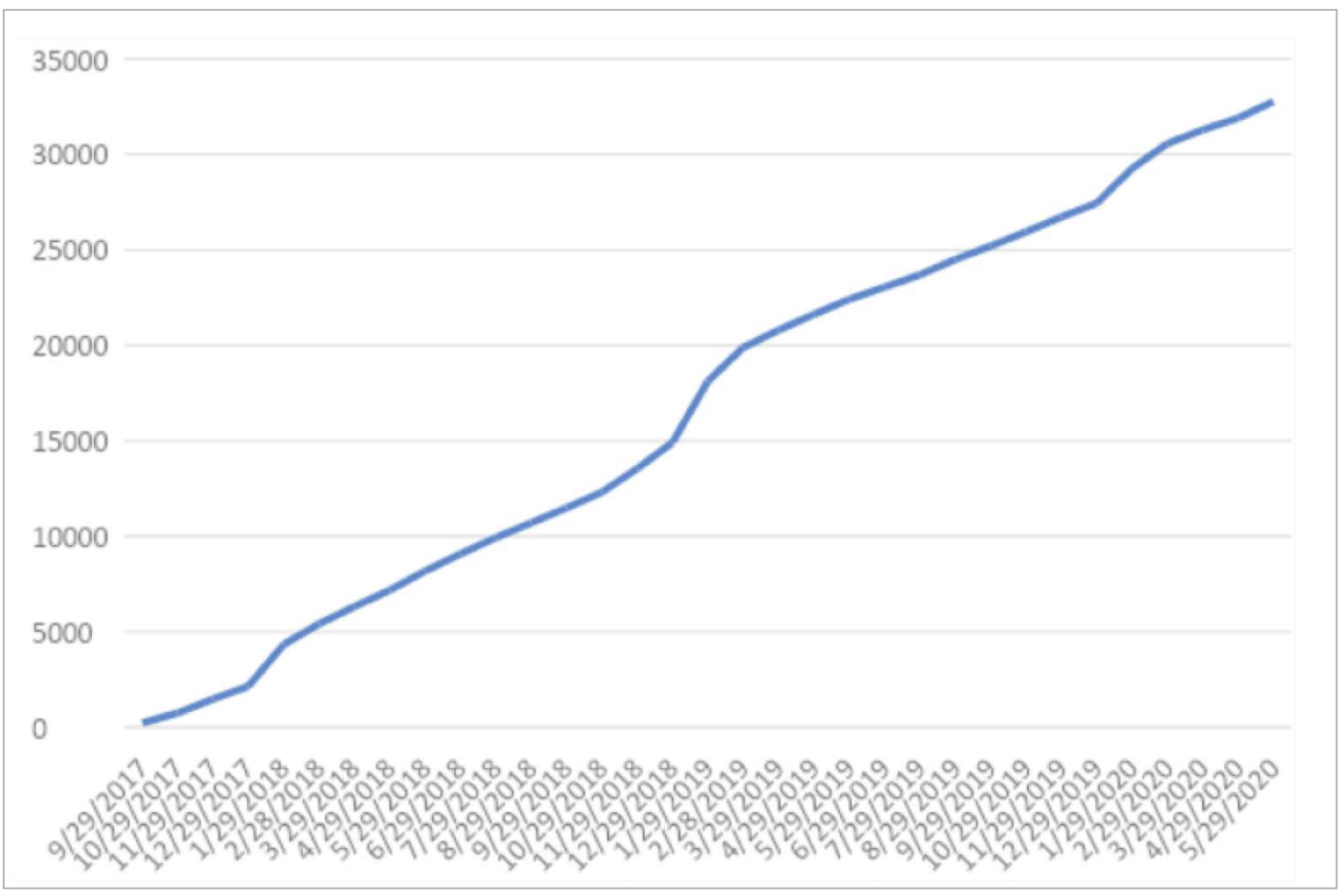

Figura 5 - Visualizações totais dos vídeos por meses do canal ‘De olho na Med', no período de setembro de 2017 a junho de 2020

Fonte: elaboração dos autores.

\section{Avaliação qualitativa a partir dos depoimentos}

O primeiro vídeo do canal foi ao ar em setembro de 2017, perfazendo um total de 17 vídeos postados até dezembro de 2018, período de execução do projeto piloto.

Os temas dos vídeos foram: custo de vida, metodologia de ensino utilizada no curso, infraestrutura da cidade, estratégias de ingresso no curso. Outros assuntos foram sugeridos pelos próprios internautas que acompanhavam o canal, tais como: o cotidiano do estudante, a rotina de estudos e aulas, a vida fora do curso do estudante de medicina, apoio estudantil, bolsas e moradia.

Os vídeos com mais visualizações foram ‘Quanto custa morar em Jataí? - Parte 1' e 'Como passei em medicina? - Transferência UFG', com 4731 e 4113 acessos até julho de 2020 respectivamente. Os vídeos mais comentados foram 'Quanto custa morar em Jataí? - Parte 1' e '10 Motivos para cursar medicina UFG'. Cada um desses recebeu respectivos 35 e 32 comentários.

A partir da análise qualitativa dos depoimentos, foi possível identificar três principais eixos temáticos em seu conteúdo: comentários de agradecimento pelo conteúdo informativo e motivador; pedidos de assuntos e dúvidas; sugestões de melhoras para o canal.

\section{Comentários de agradecimento pelo conteúdo informativo e motivador}

Este eixo temático expressa dois principais aspectos. Primeiro, o agradecimento e likes aos vídeos. Ou seja, os vídeos correspondiam às expectativas em fornecer mais informações sobre a universidade, o curso e a cidade. O segundo aspecto diz respeito à identificação e à motivação que vídeos postados inspiraram nos internautas. Os depoimentos abaixo demonstram tais questões: 
Amei o projeto de criar um canal para falar sobre o curso e a UFJ • (James Miranda Stuart Barry).

Muito obrigada por esses vídeos sobre a faculdade de medicina de jatai, está me ajudando bastante (Elisabeth Blackwell).

Que iniciativa legal. Muito obrigada, até me deu vontade de cursar medicina em Jataí (Rita Lobato).

Finalmente!!!! Parabéns para vocês. Eu procurei em todo lugar algum conteúdo de medicina de Jataí. Meu sonho é fazer medicina e eu pretendo ir pra aí. Só que estava inseguro por falta de informações. Muito obrigado por começarem esse projeto e passar essas informações pro curso (Hipócrates).

Me identifiquei muito com esse rapaz kkk. Estou no $2^{\circ}$ do EM [Ensino Médio] e já estou me preparando para os vestibulares de medicina, porém não sou aluno nota 10 , sou um aluno dedicado e creio que minha hora vai chegar (Carlos Chagas).

Considerando que este foi o eixo temático mais representativo, tanto em relação à sua recorrência na maioria dos comentários, quanto à homogeneidade do seu conteúdo, a Figura 6 apresenta nuvem de palavras mais frequentes nos comentários deste eixo.

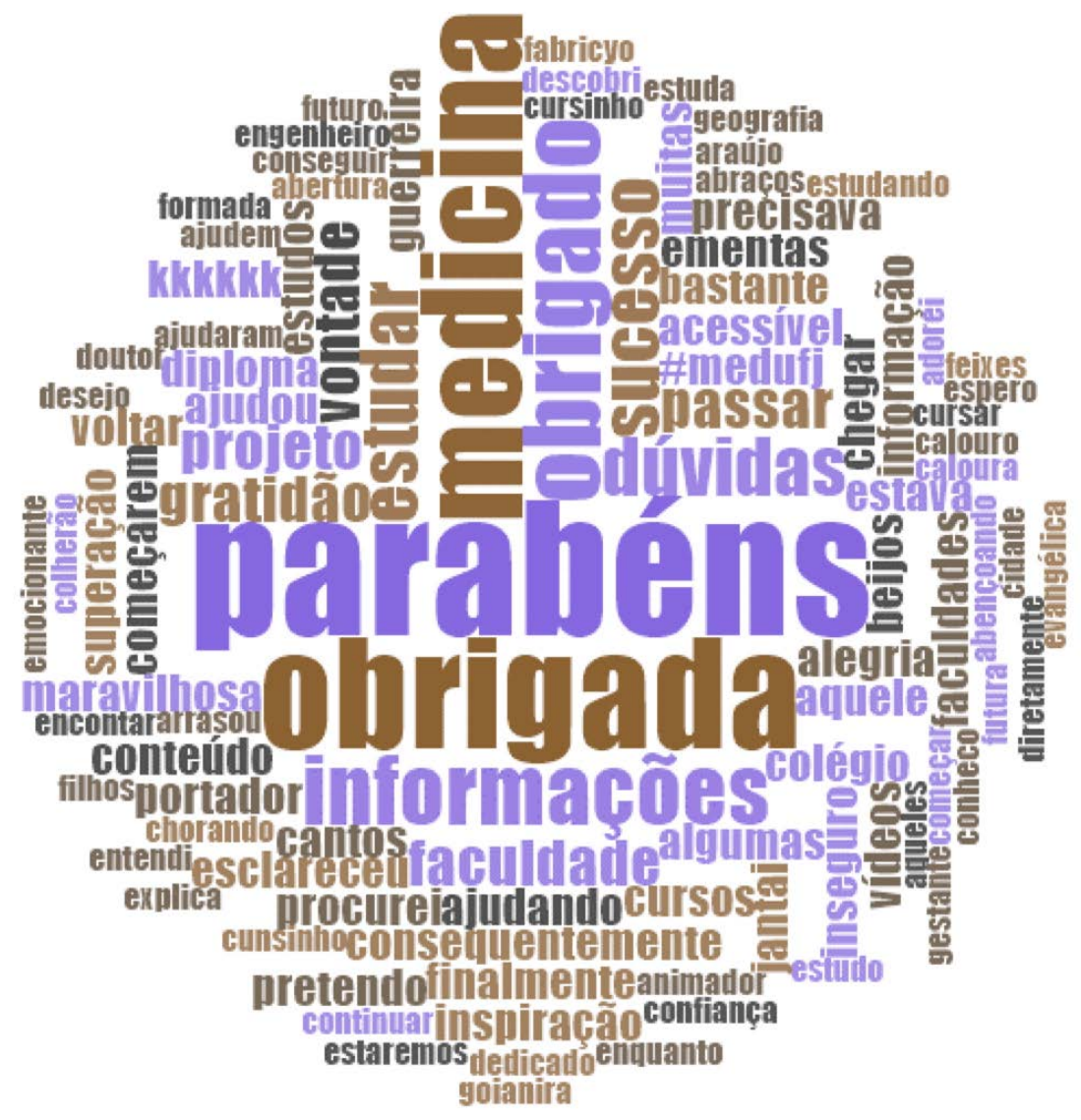

Figura 6 - Nuvem de palavras dos comentários positivos sobre agradecimentos, identificação e inspiração referentes aos vídeos do canal ‘De olho na Med', no período de setembro de 2019 a junho de 2020

Fonte: elaboração dos autores. 


\section{Pedidos de assuntos e dúvidas}

A partir da análise, foi possível evidenciar que os usuários reagiram aos vídeos solicitando assuntos a serem abordados no canal e manifestando dúvidas sobre alguns temas tratados. O quadro apresenta os principais tópicos demandados pelos internautas e respectivos comentários ilustrativos.

\section{Quadro 1 - Pedidos de temas e dúvidas para os vídeos do Canal De olho na Med, no período de setembro de 2017 a junho de 2020}

\begin{tabular}{|c|c|}
\hline Tópicos demandados & Comentários ilustrativos \\
\hline Apoio estudantil & $\begin{array}{l}\text { UFG [atual UFJ] dá algum auxílio tipo auxílio permanência, dão } \\
\text { moradia? (Adolfo Lutz) } \\
\text { Na UFG [atual UFJ] não tem assistência estudantil não? Tipo } \\
\text { moradia, alimentação e transporte (Zilda Arns) }\end{array}$ \\
\hline Cenários de prática & $\begin{array}{l}\text { Jataí já possui algum hospital escola em funcionamento ou ainda } \\
\text { em construção (Salvador Mazza) } \\
\text { Onde vocês realizam as atividades do internato? Já tem algum } \\
\text { hospital aí em Jataí ou há necessidade de deslocamento para } \\
\text { outro município? (Vital Brasil) }\end{array}$ \\
\hline Custo de vida na cidade & $\begin{array}{l}\text { Galera, qual a média de preço do aluguel aíi na cidade? Casa } \\
\text { simples } 2 \text { quartos (Françoise Barré-Sinoussi) } \\
\text { Eu vi que o custo de vida em jatai é muito alto, é verdade? (Nise } \\
\text { da Silveira) }\end{array}$ \\
\hline $\begin{array}{l}\text { Infraestrutura física da } \\
\text { universidade }\end{array}$ & $\begin{array}{l}\text { Façam um vídeo mostrando o campus. (Cicely Saunders) } \\
\text { De olho na med eu queria saber se vocês poderiam fazer um tour } \\
\text { pelo campus e pela sala de aula, pois eu quero muito conhecer. } \\
\text { (Carlota Pereira Queiroz) }\end{array}$ \\
\hline $\begin{array}{l}\text { Mecanismos de Ingresso no } \\
\text { curso }\end{array}$ & $\begin{array}{l}\text { Faz vídeo de pessoas já graduadas que passaram por } \\
\text { transferência. (Alice Hamilton) } \\
\text { Desculpa a pergunta, mas onde vocês fizeram cursinho? (June } \\
\text { Almeida) }\end{array}$ \\
\hline $\begin{array}{l}\text { Metodologia das aulas e } \\
\text { avaliações }\end{array}$ & $\begin{array}{l}\text { Grava vlog de um dia de aula de vocês (Ester Sabino) } \\
\text { Vocês têm tempo para esse estudo? (Miriam Tendler) } \\
\text { Fala como funciona as provas de vocês (Alla Levushkina) }\end{array}$ \\
\hline $\begin{array}{l}\text { Outros cursos na } \\
\text { universidade }\end{array}$ & $\begin{array}{l}\text { Alguém aqui conhece algum canal que aborda a medicina } \\
\text { veterinária da UFG [atual UFJ]? (Agnodice) } \\
\text { Pretendo fazer transferência para a UFG e gostaria de conhecer } \\
\text { mais a faculdade (Hildegarda de Bingen) } \\
\text { Só tem medicina no Campus Riachuelo [atual UFJ]? (Dorothea } \\
\text { Christiane Erxleben) }\end{array}$ \\
\hline
\end{tabular}

Fonte: elaboração dos autores.

As solicitações por informações mais detalhadas e questões sobre o apoio estudantil na universidade foram o tópico com mais comentários e pedidos. A Figura 7 apresenta nuvem de palavras que expressam este aspecto. 


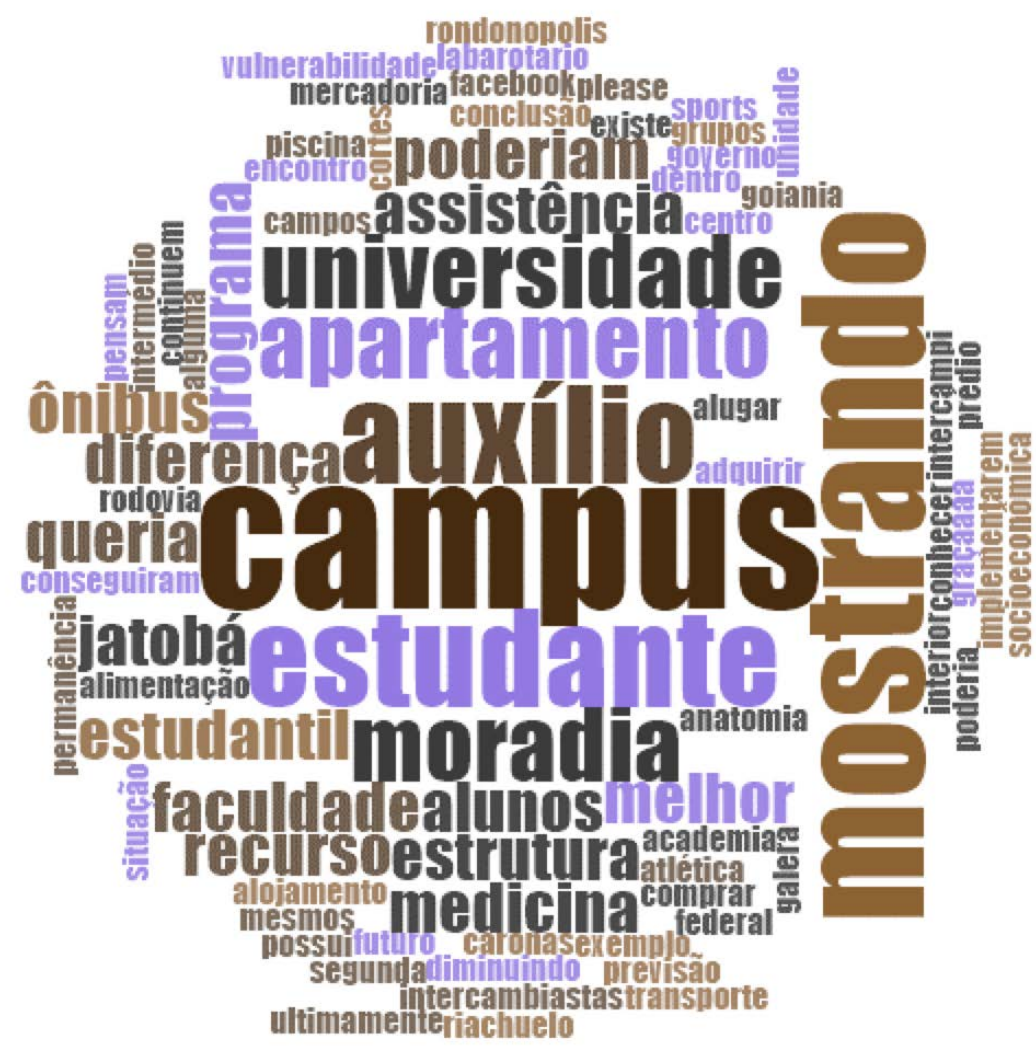

Figura 7 - Nuvem de palavras dos comentários sobre dúvidas em relação ao apoio estudantil oferecido pela universidade realizados no canal 'De olho na Med', no período de setembro de 2017 a junho de 2020

Fonte: elaboração pelos autores.

Importante salientar que houve comentários sobre sugestões de melhorias na produção dos vídeos, especialmente em relação ao volume do áudio, ângulo da câmera e vinhetas.

Muito bom o vídeo, pena que o som não tá legal (Eloisa Diaz Insunza).

Acho que vocês têm que melhorar só as Vinhetas, Que tá muito ruim (Maria Augusto G. Estrela).

Vale comentar que a partir deste projeto piloto, outras iniciativas de criação e de divulgação de conteúdo sobre o curso de medicina e a UFJ foram criadas, tais como perfis oficiais da instituição em redes sociais (Instagram e Facebook) e no próprio YouTube.

\section{DISCUSSÃO}

Com base na metodologia de ensino peer education e na sua forma dinâmica e individualizada de aplicação, o projeto foi segmentado em pequenos grupos de alunos com aptidões e interesses semelhantes para o desenvolvimento de atividades específicas. Dessa forma, o desenvolvimento das ações de cada grupo foi coordenado e executado de forma alinhada e ágil (MEASURING..., 2019). Assim como demonstrado por outros estudos (COSTA; HENTSCHKE; SILVA; BARROS et al., 2012; RIBEIRO, 2017), a oportunidade de trabalhar com pessoas de faixas etárias diferentes, com histórias e visões de mundo divergentes, capacitou a equipe para produção de conteúdo, no caso os vídeos, criativos, representativos e significativos para o público-alvo. Também contribuiu para a formação profissional e pessoal de cada aluno envolvido para além da formação acadêmica (COSTA; HENTSCHKE; SILVA; BARROS et al., 2012; RIBEIRO, 2017). 
O trabalho em equipes menores colaborou para uma melhor gestão das pessoas envolvidas em cada atividade, como a designação das responsabilidades, metodologia semelhante a outras observadas com intuito de proporcionar diversas oportunidades de aprendizado e interação (COSTA; HENTSCHKE; SILVA; BARROS et al., 2012). O desenvolvimento de trabalhos em equipe e o compartilhamento de responsabilidade trouxeram ganhos reais aos envolvidos pelo ensino/aprendizagem em pares (RIBEIRO, 2017).

Canais no YouTube voltados ao público acadêmico e estudantes no geral são relativamente comuns e apresentam características semelhantes, independentemente do tipo de conteúdo educativo produzido no canal (QUEIROGA JÚNIOR; DULCI, 2019). É possível observar pontos em comum ao se comparar o ambiente no YouTube criado para este projeto com outros bem-sucedidos, dentre os quais, ressalta-se a não moderação de comentários, que permite ao usuário da plataforma se manifestar abertamente. Outros fatores em comum são a linguagem mais acessível ao público, pois facilita a difusão do conhecimento; o uso do humor como ferramenta de aproximação entre o youtuber e os seus espectadores; divisão dos conteúdos em grupos de informações semelhantes, e produção de conteúdo com uma periodicidade pré-definida (QUEIROGA JÚNIOR; DULCI, 2019; SILVA; PEREIRA; ARROIO, 2017).

Foi observado que a metodologia empregada por outros canais de difusão de conteúdo educacional utiliza parte do tempo para divulgar atividades que vem desenvolvendo, eventos, produtos e/ou cursos (QUEIROGA JÚNIOR; DULCI, 2019). Tal divulgação está em consonância com os objetivos do canal 'De Olho na Med', cujos objetivos principais foram divulgar e promover o curso de medicina da UFJ, bem como informar as principais características do curso e da cidade.

Em relação ao público do canal, a maioria se declarou do sexo feminino, aspecto convergente com o público acadêmico do curso de medicina da UFJ, objeto do canal 'De Olho na Med'. As mulheres compõem 53,9\% do quadro discente (UFG, 2020). A atual realidade de Jataí, Goiás, reflete um panorama em ascendência global, desde os anos 2000, em países como Estados Unidos e Canadá, onde o público de estudantes de medicina é majoritariamente feminino (MINELLA, 2017). No Brasil, dados coletados de entidades médicas indicam que a maioria dos médicos formados, com idade inferior ou igual a 29 anos entre 2005 e 2015, é composta por mulheres (MINELLA, 2017).

Concernente à abrangência e dinamicidade do canal, a avaliação evidenciou uma ciclicidade de picos de acessos durante a execução do projeto piloto, com aumento de visualizações de vídeos sempre em janeiro de cada ano, durante o período de abertura do SISU. Esse incremento pode ser justificado pela busca de informações que os candidatos de todo o país fazem sobre a universidade, o curso e a cidade e seu potencial de moradia e estudo.

$\mathrm{O}$ acesso pelo SISU acontece anualmente ou semestralmente e representa uma mudança no mecanismo de admissão ao Ensino Superior. A instituição do SISU ocorreu no bojo da reformulação do Exame Nacional do Ensino Médio, que passou de um método para avaliar o desempenho dos estudantes ao fim da escolaridade básica para gradativamente ocupar papel central no quadro de políticas públicas de acesso à educação superior (LOURENÇO, 2016). Isso contribuiu para democratizar a etapa de seleção e favoreceu a participação de estudantes de baixa renda, historicamente excluída desse processo (PRATES; BARBOSA, 2015).

Tais mudanças no ingresso no Ensino Superior permitiram aos candidatos uma mobilidade acadêmica, com a oportunidade de entrada em uma universidade fora de seu estado de origem. Informações sobre a universidade e a cidade em que está localizada são importantes nestes casos (LOURENÇO, 2016). Aspecto que reforça a importância do uso das TCI, como o canal 'De Olho na Med’, para divulgação de cursos de graduação.

Nesse sentido, vale comentar sobre um dos grandes desafios atuais das Instituições Públicas de Ensino Superior e que também é um problema nacional: a evasão e vagas ociosas. Todas as universidades que 
integram o SISU têm percebido mais evasão, em que os alunos buscam a vaga pela nota e terminam ingressando numa graduação ou em uma cidade que não a de sua primeira ou segunda opção (BARROS, 2014). Este fato reforça a necessidade de divulgação e informações aos candidatos sobre a realidade de sua prospecta graduação. Dessa forma, o canal 'De Olho na Med' pode ser entendido como uma ferramenta de comunicação entre acadêmicos e interessados no curso de medicina e na universidade.

Ao considerar os comentários nos vídeos do canal, a análise evidenciou que houve trocas de informações e vivências entre os usuários e acadêmicos. Os comentários são espaços em que as pessoas compartilham suas opiniões e interagem socialmente (CORRÊA; VANZ, 2020). Constituem também um instrumento de busca a fim de se encontrar novas redes e outros tipos de conteúdo sobre a temática em questão (KHAN, 2017). Este aspecto é ilustrado pelo comentário: “Qual o Instagram de vocês??”.

Os comentários também favorecem o engajamento dos usuários por meio da troca de informações entre o canal e os espectadores. Da mesma forma, os usuários são convidados a curtir o vídeo que estão assistindo, ver outros que já foram publicados, além de se inscreverem no canal para acompanhar os novos lançamentos (REALE; MARTYNIUK, 2016). No presente relato, essa interação pode ser notada pela presença de perguntas relacionadas à existência de apoio estudantil, como são os cenários de prática, custo de vida na cidade, mecanismos de ingresso no curso de medicina e metodologias utilizadas em aulas e os critérios de avaliação. Além disso, há questionamento aos usuários sobre o conhecimento de canais que abordam outros cursos superiores ofertados pela universidade.

O engajamento, seja via comentários, likes e dislikes, é extremamente importante para o crescimento do canal, visto que vídeos com mais interações podem alcançar melhores resultados nos mecanismos de busca do YouTube (KHAN, 2017). Esta perspectiva pode ser conexa ao crescente número de acessos e visualizações dos vídeos do canal, mesmo fora do período de abertura do SISU, identificado em nossa avaliação.

As Tecnologias de Informação e Comunicação (TIC) fazem parte da experiência de ensino e aprendizagem na atualidade e também são utilizadas dentro das Universidades em projetos de extensão universitária, além do ensino e da divulgação científica. Este projeto fez uso do YouTube para produção e divulgação de conteúdos relevantes para estudantes interessados em ingressar na universidade. Baseou-se no entendimento de que tanto a educação, como outros processos de interação social, deve ser pensada no contexto do ciberespaço (RECUERO, 2009).

Outro fator relevante para a criação e manutenção de um canal em uma plataforma como o YouTube é a democratização que a plataforma proporciona ao garantir um acesso gratuito tanto para quem produz quanto para quem busca informações na internet. Assim a plataforma oferece uma possibilidade única para os educadores: um modelo de comportamento democrático (PECHANSKY, 2016). Ainda que, no Brasil, 26\% da população não tenham acesso à interne, essa plataforma garante a facilidade ao possibilitar seu uso por meio de ferramentas tecnológicas de baixa complexidade, como celulares e/ou computadores com configurações simples (CETIC, 2019).

Ainda sobre a importância de uso de tecnologias de comunicação no ambiente universitário para ensino ou para divulgação sobre o ambiente em si é relevante salientar que o estudante tem hábito de consumir conteúdo on-line para satisfazer sua curiosidade ou para dar suporte ao ensino. O estudo Impacto na Rotina Acadêmica pela Utilização de Novas Tecnologias por Estudantes de Medicina do Semiárido Paraibano traz informações sobre o uso de TIC e acesso a essas ferramentas. Em um universo de 145 estudantes, apenas 2 não possuíam acesso a um aparelho com configurações necessárias para o acesso a plataformas digitais. Dentro dessa amostra também foi evidenciado que $86,2 \%$ utilizam aplicativos para complementar os estudos e que $75 \%$ buscam na internet formas de complementar os estudos. Isso mostra como a internet faz parte da realidade do estudante e ocupa um espaço relevante nas formas de pesquisa sobre assuntos diversos (BARBOSA; CARMO; MEDEIROS; CABRAL et al, 2018). 
A comunicação direta com o público foi bastante relevante para o projeto porque permitiu observar a aceitação da audiência, bem como mapear as demandas. Por meio dos comentários do YouTube, foi possível entender se o material produzido era relevante para os inscritos. Confirmando a eficácia dessa comunicação, foi percebido que as temáticas mais procuradas e comentadas pelos futuros universitários eram sobre custo de vida na cidade. Essa demanda proporcionou a criação de mais conteúdos acerca do tema, bem como a comunicação por meio dos comentários que foram respondidos na própria plataforma com o objetivo de sanar dúvidas e aproximar estudantes e internautas.

De acordo com Castañón (2017), as principais propriedades de análise da popularidade dos vídeos no YouTube são o número de visualizações, número de comentários, número de classificações, média das classificações e número de favoritos. Porém, dentre essas métricas, a que melhor reflete de forma clara o grau de popularidade de um vídeo é, em primeiro lugar, o número de visualizações e, em segundo lugar, os comentários. Ambas foram escolhidas para analisar o desempenho do canal criado pelo projeto (CASTAÑón, 2017).

Então é possível afirmar que a análise contínua de dados, ao produzir conteúdo na internet, além de propiciar um contato direto e contínuo com o público-alvo, permite criar estratégias de produção de conteúdo e facilita o processo de autoanálise do processo criativo, garantindo assim a relevância do conteúdo e a satisfação dos internautas que acompanham o projeto. E considerando o contexto da sociedade atual é fundamental pensar e entender as relações interpessoais por meio do espaço digital.

\section{CONSIDERAÇÕES FINAIS}

O canal 'De Olho na Med' no YouTube possibilitou a comunicação direta com os usuários da comunidade em geral, especialmente estudantes interessados em ingressar no curso de medicina. Ao favorecer a troca de informações e vivências por meio dos vídeos e comentários, o canal pôde auxiliar os ingressantes no Ensino Superior na tomada de decisão, reduzindo as chances de arrependimento e consequente desistência. E, de maneira secundária, esta potencialidade do canal pode ser um mecanismo utilizado no enfrentamento do problema da evasão e aumento de vagas ociosas em cursos de Instituições Públicas de Ensino Superior.

Assim, destacamos que a utilização de estratégias de divulgação e tecnologias de informação em plataformas de grande alcance, como o YouTube, pode influenciar o processo de decisão em ao fazer parte do processo de admissão. Ou seja, divulgar um curso de medicina pela visão dos discentes pode democratizar o acesso a uma graduação de medicina, ainda marcada por preconceitos e uma redoma de suposta inacessibilidade.

\section{REFERÊNCIAS}

ADRIÃO, Maria. De jovem para jovens: educação entre pares. Rio de Janeiro: Unicef, 2010.

ARSLAN, Burak; GÖNÜLTAS, Serkan; GÖKMEN, Ersin; ÖZMAN, Oktay et al. Does YouTube include highquality resources for training on laparoscopic and robotic radical prostatectomy? World Journal of Urology, [s. I.], v. 38, n. 5, p. 1195-1199, 9 ago. 2019. DOI: https://doi.org/10.1007/s00345-019-02904-6. Disponível em: https://link.springer.com/article/10.1007\%2Fs00345-019-02904-6. Acesso em: 18 ago. 2020.

BARBOSA, Sylvio Elvis da Silva; CARMO, Larissa Araújo do; MEDEIROS, Renata Lívia Silva Fonsêca Moreira de; CABRAL, Symara Abrantes Albuquerque de Oliveira et al. Impacto na Rotina Acadêmica pela Utilização de Novas Tecnologias por Estudantes de Medicina do Semiárido Paraibano. Id on Line, Jaboatão dos Guararapes, v.12, n. 39, p. 695-712. 2018. DOI: http://dx.doi.org/10.14295/idonline.v12i39.1022. Disponível em: https://idonline.emnuvens.com.br/id/article/view/1022/1460. Acesso em: 18 ago. 2020. 
BARROS, Aparecida da Silva Xavier. Vestibular e Enem: um debate contemporâneo. Ensaio: Avaliação e Políticas Públicas em Educação, Rio de Janeiro, v. 22, n. 85, p. 1057-1090, out.-dez. 2014. DOI: https:// doi.org/10.1590/S0104-40362014000400009. Disponível em: https://www.scielo.br/scielo.php?pid=S010440362014000400009\&script=sci abstract\&tIng=pt. Acesso em 18 ago. 2020.

CASTELO BRANCO, Amanda Leal; BONTEMPO, Gínia Cezar; SARAIVA, Ana Claudia Lopes Chequer; AMARAL, Shirlena Campos de Souza. O processo de escolha por um curso superior após a "Lei de Cotas" e o Enem/Sisu: o caso dos cursos de licenciatura da UFV campus Viçosa. Revista Brasileira de Ensino Superior, Passo Fundo, v. 2, n.1, p. 21-33, jar.-mar. 2016. DOI: https://doi.org/10.18256/2447-3944/rebes. v2n1p21-33. Disponível em: http://seer.imed.edu.br/index.php/REBES/article/view/1213. Acesso em: 18 ago. 2020.

CASTAÑÓN, João Paulo de Almeida. Análise de popularidade de canais do YouTube. 2017. 50 f. Trabalho de Conclusão de Curso (Graduação em Sistemas de Informação) - Instituto de Ciências Exatas e Aplicadas, Universidade Federal de Ouro Preto, Ouro Preto, 2017.

\section{CENTRO REGIONAL DE ESTUDOS PARA O DESENVOLVIMENTO DA SOCIEDADE DA INFORMAÇÃO (CETIC). Pesquisa sobre o Uso das Tecnologias de Informação e Comunicação nos Domicílios Brasileiros - TIC Domicílios. [S. I.; s. n.], 2019.}

CORRÊA, Maurício de Vargas; VANZ, Samile Andréa de Souza. A formação do capital social no YouTube: estudo com base em um canal de divulgação científica de questões abordadas pela psicologia. Revista Eletrônica de Comunicação, Informação e Inovação em Saúde, Rio de Janeiro, v. 14, n. 1, p. 167-183, jan.mar. 2020. DOI: https://doi.org/10.29397/reciis.v14i1.1756. Disponível em: https://www.reciis.icict.fiocruz.br/ index.php/reciis/article/view/1756. Acesso em: 18 ago. 2020.

FIOROTTI, Karoline Pedroti; ROSSONI, Renzo Roldi; MIRANDA, Angélica Espinosa. Profile of medical students at the Federal University in Espírito Santo, Brazil, 2007. Revista Brasileira de Educação Médica, Rio de Janeiro, v. 34, n. 3, p. 355-362, jul.-set. 2010. DOI: https://doi.org/10.1590/S0100-55022010000300004. Disponível em: https://pdfs.semanticscholar.org/c8a6/a47159036ec2a98f88c40de350ea8e6b4c87.pdf. Acesso em: 18 ago. 2020

FONTOURA, Odir. Narrativas históricas en disputa: un estudio de caso de YouTube. Estudos Históricos (Rio de Janeiro), Rio de Janeiro, v. 33, n. 69, p. 45-63, jan.-abr. 2020. DOI: https://doi.org/10.1590/ s2178-14942020000100004. Disponível em: http://www.scielo.br/scielo.php?script=sci_arttext\&pid=S010321862020000100045\&lng=en\&nrm=iso. Acesso em: 18 jul. 2020.

GERMANO, Joelia Celeste Vieira. Perfil dos estudantes do Curso de Medicina da Escola Multicampi de Ciências Médicas do Rio Grande do Norte/UFRN. 2017. 56 f. Dissertação (Mestrado profissional em Ensino na Saúde) - Centro de Ciências da Saúde, Universidade Federal do Rio Grande do Norte, Natal, 2017.

QUEIROGA JÚNIOR, Tarcísio Moreira; DULCI, Tereza M. Spyer. "Professores-Youtubers":: análise de três canais do Youtube voltados para o ensino de História. Escritas do Tempo, v. 1, n. 1, p. 4-29, mar.-jun. 2019. DOI: https://doi.org/10.47694/issn.2674-7758.v1.i1.2019.0429. Disponível em: https://periodicos.unifesspa.edu. br/index.php/escritasdotempo/article/view/410. Acesso em: 18 ago. 2020.

KHAN, M. Laeeq. Social media engagement: what motivates user participation and consumption on YouTube?. Computers in Human Behavior, [s. I.], v. 66, p. 236-247, jan. 2017. DOI: https://doi.org/10.1016/j. chb.2016.09.024. Disponível em: https://www.sciencedirect.com/science/article/pii/S0747563216306513. Acesso em 17 ago. 2020.

LIBARDI, Mônica Beatriz Ortolan; DUARTE, Júlia Maria de Oliveira; LIMA, Josilene Albino de Freitas; MONTEIRO, Sandra de Nazaré Costa et al. Comunicação em saúde por meio doambiente virtual: relato de experiência. Revista Gaúcha de Enfermagem, Porto Alegre, v. 39, e20170229, out. 2018. DOI: https:// doi.org/10.1590/1983-1447.2018.20170229. Disponível em: https://www.scielo.br/scielo.php?script=sci arttext\&pid=S1983-14472018000100801\&tIng=pt. Acesso em: 18 ago. 2020.

LOURENÇO, Vânia Maria. Limites e possibilidades do Enem no processo de democratização do acesso à educação superior brasileira. 2016. 145 f. Dissertação (Mestrado Profissional em Educação) Universidade de Brasília, Brasília, 2016.

MEASURING digital development - Facts and figures 2019. Geneva: International Telecommunication Union Publications, 2019. Disponível em: https://news.itu.int/measuring-digital-development-facts-figures-2019/. Acesso em: 18 ago. 2020. 
MINAYO, Maria Cecília de Souza. O desafio do conhecimento: pesquisa qualitativa em saúde. São Paulo: Hucitec, 2014.

MINELLA, Luzinete Simões. Medicina e feminização em universidades brasileiras: o gênero nas interseções. Revista Estudos Feministas, Florianópolis, v. 25, n. 3, p. 1111-128, set.-dez. 2017. DOI: https://doi. org/10.1590/1806-9584.2017v25n3p1111. Disponível em: https://www.scielo.br/scielo.php?pid=S0104026X2017000301111\&script=sci_arttext. Acesso em: 18 ago. 2020.

NUNES, Antônio Carlos da Costa; FAVACHO, André Márcio Picanço. O discurso da mídia das instituições privadas de Ensino Superior e a produção do sujeito universitário. Pro-Posições, Campinas, v. 30, e20170101, jul. 2019. DOI: https://doi.org/10.1590/1980-6248-2017-0101. Disponível em: https://www.scielo.br/ scielo.php?pid=S0103-73072019000100511\&script=sci arttext. Acesso em: 18 jul. 2020.

PECHANSKY, Rafaela Chiapin. O YouTube como plataforma educacional: reflexões acerca do canal Me Salva. In: CONGRESSO DE CIÊNCIAS DA COMUNICAÇÃO NA REGIÃO SUL, 17., 26-28 maio 2016, Porto Alegre. Anais [...]. São Paulo: Intercom, 2016. p. 1-13.

PELLEGRINI, Dayse Pereira; REIS, Diolinda Dias; MONÇÃO, Philipe Costa; OLIVEIRA, Rafael. YouTube: uma nova fonte de discursos. [S. l.; s. n.], 2010. Disponível em: http://bocc.ubi.pt/pag/bocc-pelegrinicibercultura.pdf. Acesso em: 18 ago. 2020.

COSTA, Bartira Ercília Pinheiro da; HENTSCHKE, Marta Ribeiro; SILVA, Aline Cristina Cruz da; BARROS, Annerose et al. Reflections on the importance of the informal curriculum of the medical student. Scientia Medica, Porto Alegre, v. 22, n. 3, p. 162-168, 2012. Disponível em: https://revistaseletronicas.pucrs.br/ojs/ index.php/scientiamedica/article/view/10052. Acesso em: 9 set. 2020.

PRATES, Antônio Augusto Pereira; BARBOSA, Maria Ligia de Oliveira. A expansão e as possibilidades de democratização do Ensino Superior no Brasil. Caderno CRH, Salvador, v. 28, n. 74, p. 327-339, maioago. 2015. Disponível em: https://www.scielo.br/scielo.php?pid=S0103-49792015000200327\&script=sci abstract\&tlng=pt. Acesso em: 18 ago. 2020.

REALE, Manuela Vieira; MARTYNIUK, Valdenise Lézier. Divulgação Científica no YouTube: a construção de sentido de pesquisadores nerds comunicando ciência. In: CONGRESSO BRASILEIRO DE CIÊNCIAS DA COMUNICAÇÃO, 39., 4-6 set. 2016, São Paulo. Anais [...]. São Paulo: Intercom, 2016. p. 1-15.

RECUERO, Raquel. Redes sociais na internet. Porto Alegre: Sulina, 2009.

REGO, Rhyan Meninea do; MARQUES, Natália Alves; MONTEIRO, Perla da Costa; OLIVEIRA, Céres Larissa Barbosa de et al. O perfil atual do estudante de Medicina e sua repercussão na vivência do curso. Pará Research Medical Journal, Belém, v. 2, n. 1-4, e05, 2018. DOI: http://dx.doi.org/10.4322/prmj.2018.005. Disponível em: https://www.prmjournal.org/article/doi/10.4322/prmj.2018.005. Acesso em: 18 ago. 2020.

RIBEIRO, Joana Fernandes. Aprendizagem Assistida por Pares: uma alternativa pedagógica no ensino de competências a estudantes de Medicina. 2017. 15 f. Dissertação (Mestrado integrado em Medicina) Universidade de Coimbra, Coimbra, 2017.

SILVA, Beatriz Amorim de Azevedo e; GRILLO, Sheila Vieira de Camargo. Novos percursos da ciência: as modificações da divulgação científica no meio digital a partir de uma análise contrastiva. Bakhtiniana: Revista de Estudos do Discurso, São Paulo, v. 14, n. 1, p. 51-73, jan.-mar. 2019. DOI: https://doi.org/10.1590/2176457336377. Disponível em: https://www.scielo.br/scielo.php?pid=S2176-45732019000100051\&script=sci arttext. Acesso em: 18 ago. 2020.

SILVA, Marcelo José da; PEREIRA, Marcus Vinicius; ARROIO, Agnaldo. O papel do YouTube no ensino de ciências para estudantes do ensino médio. Revista de Educação, Ciências e Matemática, v. 7, n. 2, p. 3555, nov. 2017. Disponível em: http://publicacoes.unigranrio.edu.br/index.php/recm/article/view/4560/2524. Acesso em: 18 ago. 2020.

UNIVERSIDADE FEDERAL DE GOIÁS. Relatório do perfil dos estudantes de Medicina da Universidade Federal de Jataí. [S. I.; s. n.], 2020.

TAPIA-JARA, Jonathan; SÁNCHEZ-ORTíZ, Aurora; VIDAL-SILVA, Cristian. Estilos de aprendizaje e intención de uso de videos académicos de YouTube en el contexto universitario chileno. Formación universitaria, La Serena, v. 13, n. 1, p. 3-12, fev. 2020. DOI: http://dx.doi.org/10.4067/S0718-50062020000100003. Disponível em: https://scielo.conicyt.cl/scielo.php?pid=\$0718-50062020000100003\&script=sci_arttext\&tlng=en. Acesso em: 18 ago. 2020. 